\title{
PROMOTING GROUP CREATIVITY IN UPSTREAM REQUIREMENTS ENGINEERING
}

\author{
Rosalie J. Ocker \\ College of Information Sciences and Technology \\ The Pennsylvania State University, USA
}

\begin{abstract}
The upstream stage of requirements engineering (RE) focuses primarily on determining high-level organizational requirements. Upstream RE provides perhaps the best opportunity to instill creativity into the design process, since it is where stakeholders figure out what to build. However, exactly how to incorporate creativity into current RE methods remains a fundamental concern. Negative social influences, such as those associated with status differentials, ingroup bias, and majority influence, can impede group creativity and otherwise negatively impact the upstream RE process. This paper discusses these issues. Two IBIS-based design rationale approaches are presented and suggestions for diminishing the potential for negative social influences are offered.
\end{abstract}

Keywords: Social influence, creativity, design rationale, requirements engineering.

\section{UPSTREAM REQUIREMENTS ENGINEERING}

The upstream stage of requirements engineering (RE) focuses primarily on determining high-level organizational requirements. The process begins with an often ill-defined, unstructured problem and works towards a feasible problem definition and then to a set of high-level requirements. Determining upstream requirements is typically an intensive collaborative process of communication and negotiation (Holtzblatt \& Beyer, 1995) among heterogeneous stakeholders, consisting of users, designers, project sponsors and other effected parties. Each stakeholder group brings its unique perspective to this process; thus, knowledge acquisition, sharing, and integration must be accomplished to develop a mutually shared understanding (Waltz, Elam, \& Curtis, 1993).

Upstream RE provides perhaps the best opportunity to instill creativity into the design process (Couger, 1996) since it is where stakeholders figure out what to build. However, exactly how to incorporate creativity into current RE methods remains a fundamental concern since current methods rarely include processes to encourage creativity (Nguyen \& Swatman, 2006). Furthermore, reaching a stage of shared understanding and eliciting high-level requirements can be laden with negative intergroup social processes, such as status differentials, ingroup bias, and majority influence at the expense of minority influence (Ocker, 2007a). These social influences can thwart creativity and otherwise negatively impact the upstream RE process (Ocker, 2005, 2007b).

(C) 2010 Rosalie Ocker and the Agora Center, University of Jyväskylä

URN:NBN:fi:jyu-20105241907 
This paper seeks to offer insight into how creativity can be encouraged during upstream RE by addressing and diminishing negative social influences between (and within) stakeholder groups. This paper is organized as follows: The next section reviews individual and group-level creativity and discusses how social influences impact creativity. Then group support systems and electronic brainstorming are discussed within the context of social influences. Finally, the IBIS approach to design rationale is discussed. The paper ends with suggestions for integrating Group Support Systems (GSS) with anonymous electronic brainstorming and anonymous voting into two IBIS based DR approaches.

\section{CREATIVITY AND SOCIAL INFLUENCES}

Creativity is a complex interaction of person and situation that takes places at both the individual and group levels. Creativity at the individual level is a function of antecedent conditions (e.g., the home environment), personality, knowledge about the task, motivation, and cognitive style/abilities (Amabile, 1988, 1990; Barron \& Harrington, 1981; Carrol, 1985; Guilford, 1977). Concerning styles/abilities, a substantial body of research has focused on the divergent production of ideas as the dominant cognitive link to creativity. Divergent thinking progresses away from a problem in a variety of different directions and involves breaking down barriers and restrictions on thoughts. Convergent thinking, on the other hand, involves progression towards a single answer (Thompson, 2003). The cognitive processes of fluency, flexibility, originality, and elaboration have been identified as essential to the divergent production of ideas (Guilford, 1984). Personality traits associated with creativity include independent thought and judgment, autonomy, persistence, self-confidence, intellectual honesty, and an internal locus of control (e.g., Amabile, 1988; Barron \& Harrington, 1981; Woodman \& Schoenfeldt, 1989).

Creativity at the team level is more likely to occur when the composition of the team includes "stimulating colleagues" (Parmeter \& Gaber, 1971). Heterogeneous teams composed of individuals who bring a range of knowledge, ideas, and approaches to problem solving improve the teams' creative performance (Hoffman, 1959; Hoffman \& Maier, 1961). Diversity in terms of areas of specialization and work responsibilities are especially relevant to enhanced team creativity.

West (1990) proposed that creative teams operate in an environment of participative safety and foster a climate for excellence. Collaboration that occurs in a nonjudgmental and supportive team atmosphere engenders a feeling of interpersonal safety among participants. West reasoned that this nonthreatening atmosphere promotes creativity because members are more likely to risk proposing new ideas.

A climate for excellence refers to a team atmosphere where a mutually shared concern for performance excellence pertaining to a vision or outcome thrives. A tolerance for diversity of opinion and constructive conflict are the hallmarks of this climate; opposing opinions are not only offered, but also are debated and critiqued by team members (King \& Anderson, 1990).

\section{Social Influences}

The qualities and characteristics associated with group creativity are influenced by the social conditions and context in which the creative situation occurs. Group-level creativity is impacted by a number of factors that come into play when individuals collaborate. These include the member 
composition of the group, characteristics of the group, such as the degree of trust and cohesiveness, and the group collaboration context (e.g., degree of virtuality or physical distance between group members and means of communication; Woodman, Sawyer, \& Griffin, 1993). Interaction between individuals and groups are impacted by social influences. Woodman et al. argue that social influences stemming from cross-level interactions between individuals and groups are critical to understanding the enhancers and inhibitors impacting creativity at the group level.

The pervasiveness of social influences within a group is described by Vinacke, Wilson, and Meredith (1964):

In a very real sense, any interaction between or among persons can be viewed as a social influence process. It would be hard, certainly, to think of a social setting in which at least one person is not attempting to bring about some desired response in another. Even ordinary conversations have this characteristic. (p. 259)

A discussion of the social influences that have the potential for impact on a group's creativity is presented next. Specifically, status, social identity and ingroup bias, majority influence, and minority influence are presented. Table 1 contains a description of each social influence and its potential impact on creativity.

\section{Status}

A status characteristic is any characteristic that influences a group member's own or others' evaluations and beliefs about that group member. As delineated by Cohen and Zhou (1991),

Status characteristics can be "diffuse" (i.e., hold over a wide range of situations and performances), or be "specific", (i.e., limited to a particular situation, or task). Status characteristics may be external to the interaction or may emerge in the course of task interaction; they may be explicitly relevant to the group task or they may become relevant in the course of interaction. Gender, race, and military rank are examples of diffuse characteristics that are external to the group interaction. Mathematical ability is a specific status characteristic that is explicitly relevant to solving mathematical problems and may become relevant to a whole range of verbal and nonverbal tasks. (p. 180)

Table 1. Social Influences and their Potential Effect on Creativity.

\begin{tabular}{|c|c|c|}
\hline $\begin{array}{l}\text { Social } \\
\text { Influence }\end{array}$ & Description & $\begin{array}{c}\text { Potential } \\
\text { Creativity } \\
\text { Effect }\end{array}$ \\
\hline Status & $\begin{array}{l}\text { Status hierarchies result in inequalities in interaction; higher status } \\
\text { members have more influence than lower status members. }\end{array}$ & Reduces \\
\hline $\begin{array}{l}\text { Social } \\
\text { Identity }\end{array}$ & $\begin{array}{l}\text { Members categorize themselves into "us vs. them" subgroups. } \\
\text { Subgroups develop separate identities leading to ingroup bias } \\
\text { (increased interaction with and preferential behavior towards members } \\
\text { of one's subgroup). }\end{array}$ & Reduces \\
\hline $\begin{array}{l}\text { Majority } \\
\text { Influence }\end{array}$ & $\begin{array}{l}\text { Majority opinion-holders influence minority opinion-holders who re- } \\
\text { caste their views to conform to majority; promotes convergent thinking. }\end{array}$ & Reduces \\
\hline $\begin{array}{l}\text { Minority } \\
\text { Influence }\end{array}$ & $\begin{array}{l}\text { Minority opinion-holders influence majority opinion-holders; promotes } \\
\text { independent and divergent thinking. }\end{array}$ & Increases \\
\hline
\end{tabular}


Status characteristics theory (SCT) suggests that individuals combine status information of group members to form expectations of their collective performance (see Wagner \& Berger, 1993, 1997, for summaries). In this way, status hierarchies are formed within a given group, which result in inequalities in interaction such that higher status individuals initiate and receive more interaction and have more influence than lower status members. For lowstatus members to attain some level of influence, they must show more evidence of ability than high-status members (Biernat \& Kobrynowicz, 1997).

SCT has relevance for the composition of a given group. It is not the status of the individuals within a group, per se, that organizes member interaction. Rather, it is the composition of the group with regard to the status differentials between members (Sell, Lovaglia, \& Mannix, 1992). Moreover, the more divergence between the states of a status characteristic (e.g., a team of four males and a female is likely to be more divergent than a team of two males and a female), the more impact the status characteristic has on group interaction (Kanter, 1977; Moreland \& Levine, 1992).

A structural approach also has been used to account for behavior due to status differences. The theory of proportional representation posits that the numerical representation of a status type (e.g., race, sex) - that is, the relative numbers of a given status indicatorinfluences interaction (Kanter, 1977). According to Kanter, those in the numerical majority control the group and its culture. Skewed groups are those whose membership has a preponderance of one status type over another. In skewed groups, a member from the nondominant category may experience feelings of isolation and powerlessness. This may lead to behavior by the nondominant members that tends towards passive and inhibited conduct.

\section{Social Identity and Ingroup Bias}

Social categorization theory (Tajfel, 1981) and social identity theory (SIT; Tajfel, 1978; Tajfel \& Turner, 1986; Turner, 1981) suggest that people derive social identity primarily from membership in groups (not to be confused with team membership). For example, demographic differences can result in people categorizing themselves into "us vs. them" groupings. In such situations, positive social identity results when one can make favorable comparisons between the group to which one is a perceived member (i.e., the ingroup), as compared to other germane groups to which one is not a perceived member (i.e., the outgroups).

Decades of research indicates that subgroups form due to diversity in terms of demographic attributes (e.g., race, age, sex), psychological differences (e.g., beliefs), and affiliations (for a comprehensive review, see Williams \& O'Reilly, 1998). In team dynamics, subgroups develop separate identities and exhibit ingroup bias - that is, increased interaction with and preferential behavior towards members of one's subgroup, reduced trust and team cohesiveness, and increased conflict between subgroups - which impairs team effectiveness and performance (e.g., Lott \& Lott, 1965; O’Reilly, Caldwell, \& Barnett, 1989; Smith et al., 1994).

A fault line divides a group's members according to one or more attributes (Lau \& Murnighan, 1998), as depicted in Figure 1. The more attributes that are aligned along the same fault line, the stronger the fault line, and the resulting distinction between subgroups. For example, if a team is composed of male engineers and female marketing professionals, it has a stronger fault line than if the engineering and marketing groups were composed of both males and females. Thus, rather than the amount of diversity within a team, Lau and 
Murnighan (1998) argue that it is the alignment or correlation (Cramton \& Hinds, 2005) of member attributes that increases the strength of the division between subgroups.

The configuration of a team also has been shown to create a fault line. For example, when team members are spread across multiple locations, subgroups tend to form according to location, resulting in ingroup bias (Ocker, Huang, Benbunan-Fich, \& Hiltz, in press; Panteli \& Davison, 2005; Polzer, Crisp, Jarvenpaa, \& Kim, 2006). The number of team locations can affect the degree of ingroup bias: For example, teams configured across two locations have been found to exhibit stronger ingroup dynamics compared to teams with three locations (Polzer et al., 2006). Additionally, when a team includes both colocated members and isolated members, ingroup dynamics can still prevail (Polzer et al., 2006). Bos, Shami, Olson, Cheshin, and Nan (2004) found that colocated members formed one subgroup, while the isolates banded together to form their own subgroup.

\section{Majority Influence}

Groups have a need for uniformity of opinion. Moscovici (1974) asserts that this is due to two primary reasons. First, since groups normally have a purpose, the group feels the need to move in a certain direction to achieve that purpose, which is much easier to accomplish when group members hold similar opinions. Second, groups have a need for a sense of social reality, which is achieved through the validation of one's own judgments and opinions by the other members of the group. To achieve uniformity, groups typically exclude deviance and are unwilling to compromise (Asch, 1951; Festinger, 1950, Sherif, 1935).

Majority influence is a type of social influence centered on conformity, which entails movement in beliefs and behavior toward the group. The act of conforming requires two parties: the majority group and the minority individual or subgroup. The majority has its own set of beliefs and definitions for acceptable behavior - in essence, its rules and norms. Cohesion within the group reaffirms the belief and acceptance of previously made decisions, and prohibits the acceptance or adherence to other norms. Conformity within the group serves to absorb any deviance by the minority, as deviance is seen as a threat to the majority. The function of conformity is successfully fulfilled when (a) the majority of the group has a well-defined set of norms, responses, and attitudes, and (b) the group exerts social pressure on the individual or subgroup that lacks well-established norms. Majority influence prevails when deviant individuals or subgroups recast their views or behaviors to conform to those of the group (Moscovici, 1974).

In general, research has found that what contributes most to conformity is the existence of unanimous agreement (e.g., Graham, 1962; Mouton, Blake, \& Olmstead, 1956). Thus, yielding to the majority, although influenced by various factors such as size or shared power of the majority, is credited to the primary influence that a perceived consistency of the majority opinion has on

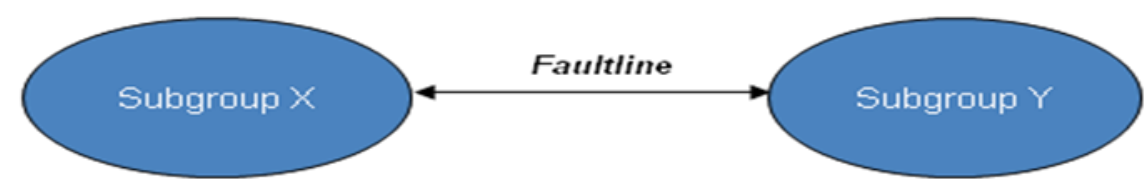

Figure 1. Subgroups divided by a fault line. 
the minority. It is this attribute that is believed to cause the minority opinion holder to succumb to the majority opinion.

Normalization is the process whereby the "reciprocal influence of group members induces them to formulate or to accept a compromise" (Moscovici, 1974, p. 208). Individuals attempt to create an internal reference point - a norm or standard - when an external norm or standard is lacking (Sherif, 1935). In considering the case in which the majority of individuals do not have a well-defined norm or solution, Moscovici (1974) described the process of normalization:

When a number of individuals are confronted by a set of objects or stimuli which they are supposed to judge or a problem which they are supposed to solve and there are no particular norms or rules to govern their behavior, each of the individuals is hesitant and relatively inconsistent. As soon as they begin discussing the situation or making their judgments, each of them becomes aware of the discrepancies among themselves. Since they have no motivation to increase their uncertainty by widening their differences, nor to provoke conflict between themselves, they generally follow the road of compromise. This compromise generally leads to the establishment of an average judgment or response. This is what is called the normalization process. (p. 224).

The development of a norm or standard is due to the need for stability that is provided by a frame of reference within which responses can be organized. Moscovici asserted that the normalization process occurs in order to avoid conflict and disagreement, and therefore is not necessarily a result of cooperation and mutual understanding within the group. Again, convergent, rather than divergent, thinking is prevalent.

\section{Minority Influence}

Minority influence describes the situation where minority opinion holders influence the opinions of the majority opinion holders. Thus, the situation is similar to that of majority influence, although in this case the minority exerts influence on the majority. Conflict and behavioral style are important aspects in the development of minority influence on a group. Moscovici and Nemeth (1974, p. 220) asserted that it is the behavioral style, that is, the "orchestration and patterning of the minority's behavior" that is at the root of the minority's influence. They explained,

It is such behavioral styles that cause the majority to question its own position and consider the possibility that the minority may be correct. When such patterning leads to assumptions that the minority is consistent and certain of its position, that it is objective and unbiased in its judgments, then the minority can be effective. (p. 220)

Maass and Clark (1984) pointed out that,

Since Sherif's (1935) and Asch's (1951) early work on conformity, it has become a social psychological truism that individuals tend to yield to a majority position even when that position is clearly incorrect. Conformity became a term nearly equivalent in meaning to social influence. It was not until 1969 that Moscovici and his coauthors pointed out that social influence is by no means limited to a one-direction dependency of the minority on the majority... a consistent minority is able to exert a remarkable degree 
of influence even when it is not equipped with such characteristics as power, status, competence (Hollander, 1964). (p. 428)

Nemeth (1986) made a connection between creativity and minority influence. In a series of studies, Nemeth and colleagues found that minority influence stimulated independent and divergent thought, so that issues and problems were considered from more perspectives. This resulted in group members detecting and exploring not only new solutions, but correct solutions. Nemeth explained the process as follows:

\begin{abstract}
When the influence source is a minority, the assumption that the minority is incorrect and the disinclination to publicly adopt its position lead to an initial dismissal of the minority viewpoint. However, with consistency and confidence on the minority's part over time, people are stimulated to understand such alternative views (e.g. "How can they be so wrong and yet so sure of themselves?"). As a result, they are stimulated to reappraise the entire situation, which involves a consideration of numerous alternatives, one of which is the position proposed by the minority. As such, the thought processes are marked by divergence and, hence, the potential for detecting novel solutions or decisions. (Nemeth, 1986, p. 26)
\end{abstract}

Nemeth thus offered a reconceptualization of minority influence. "The implications for creativity and decision making, both at the individual and group levels, become considerable" (Nemeth, 1986, p. 25).

\title{
Group Support Systems and Brainstorming
}

Can technology assist in overcoming the negative social influences that can thwart creativity in groups? A recent study indicates the usefulness of a group support system (GSS) in workgroups with distinct social identities (Lim \& Guo, 2008). A GSS incorporates computer technology with communication and decision processes in support of group problem-solving and decision-making activities. Historically, GSSs were designed for same-time, same-place meetings where each meeting participant has his/her own computer monitor and keyboard (see Fjermestad \& Hiltz, 1998, 2000, for in-depth reviews). In a "decision room" GSS, a meeting facilitator assists the group in all activities, from providing technical support to chairing the GSS session, and in moving the group through a planned agenda.

A GSS typically includes a toolkit to assist groups in performing their activities. A system might include a planning tool, an electronic brainstorming tool, and various voting tools. For example, GroupSystems, ${ }^{1}$ arguably the most extensively used and studied GSS, includes a series of tools to support electronic brainstorming for groups. A comparison of traditional and electronic brainstorming provides a good example of how technology and process can alter the affects of social influences on the creative process.

\section{Traditional Brainstorming}

As originally devised, traditional brainstorming (face-to-face, no technology support) involves four rules designed to reduce negative social influences so as to increase idea generation and group creativity (Osborn, 1963). These rules are 
- Focus on quantity: This rule is based on the axiom that quantity leads to quality. By increasing the number of ideas generated, it is assumed that there is a greater chance of generating a creative and effective solution.

- Withhold criticism: By withholding criticism, the expectation is that participants will be more likely to submit far-fetched, radical, and even possibly "silly" but potentially stimulating ideas to the group.

-Welcome unusual ideas: To encourage "out of the box" thinking, participants are encouraged to forego assumptions and look at the problem from new perspectives.

- Combine and improve ideas: Ideas can be merged to form new, "better" ideas, following the maxim that $1+1=3$.

Osborn's claims that traditional face-to-face brainstorming groups produce more and better ideas than the same number of people working alone have been refuted time and again (see Mullen, Johnson, \& Salas, 1991, for a review). Two explanations have been offered regarding this phenomenon (Diehl \& Stroebe, 1987). Production blocking occurs when participants must wait to convey their ideas to the group because another member is speaking. During this waiting period, it is speculated that the silent participants forget their ideas or self-censor, resulting in the loss of a significant number of their ideas. Evaluation apprehension stems from a fear of disapproval by others (Cottrell, 1972) that results in participants holding back ideas. Social loafing, also known as free-riding, is the tendency of participants to put forth less effort in group settings than they would if working individually (Latane, 1981).

\section{Electronic Brainstorming Using GSS}

Using a GSS, electronic brainstorming (EBS) attempts to address the shortcomings of traditional brainstorming by blending a component of the nominal group technique (the ability to generate ideas without interruption) with a component of traditional brainstorming (sharing ideas with other participants). The typical EBS process includes steps for generating ideas, editing ideas, and evaluating ideas in a decision-room type GSS context (Gallupe \& Cooper, 1993). Anonymous EBS is a variation that, as the name implies, eliminates the association between a participant and his/her ideas, edits, and evaluations.

When generating ideas, members type an idea into the GSS and hit enter, at which point the idea is disseminated to the group. Members receive others' ideas randomly. In terms of editing ideas, the GSS includes a sort feature that enables members to organize ideas by keywords, and then combine ideas or delete redundant ideas. The evaluation of ideas is typically accomplished by voting. In rank order voting, each participant can individually prioritize the idea list. The GSS then takes these individual rankings and creates a group ranking based on all members' rankings. Any number of votes can occur in an effort to reach consensus on the priority of ideas.

Parallel entry and anonymity are important in addressing the limitations of traditional brainstorming (Connolly, Jessup, \& Valacich, 1990). Production blocking is addressed through parallel entry, the ability of participants to simultaneously enter and share ideas. In anonymous EBS, evaluation apprehension and social loafing are reduced because participants share and evaluate ideas without being identified, free from the fear of criticism (given a large-enough pool of participants). Thus, anonymous EBS separates ideas from the status of their proposers and, as such, promotes equalized power within the group. Furthermore, the 
opportunity for minority influence is potentially enhanced, not only by separating ideas from proposers, but also by increasing the opportunity for the minority to be "heard," since there is no opportunity for the majority opinion holders to shut out the minority.

\section{Design Rationale: IBIS to Support Argumentation}

Traditionally, design rationale (DR) has been applied to RE since it epitomizes the "wicked" types of problems addressed by Rittel and Weber (1973). DR provides a structure for focusing discussion among the different stakeholders within a project team. DR originates from two areas: early studies of design activity conducted by Kunz \& Rittel (1970) and argumentation as developed by Toulmin (1958). However, Rittel was the first to advocate systematic documentation of DR as part of the design process.

Rittel's approach to design reasoning is based on argumentation, and thus is concerned with supporting debate and discussion. Rittel developed a method to represent (a) a network of issues (design questions); (b) selected and reflected answers; and (c) arguments for and against these answers. The outcome of his work was IBIS (Issue-Based Information System) that is a method, not a computerized information system, for supporting the reasoning process required in design and other wicked problems.

The objective of an IBIS discussion is for each of the stakeholders to try to understand the specific elements of each other's proposals. Initially, an unstructured problem area or topic is presented.

About this topic and its subtopics a discourse develops. Issues are brought up and disputed because different positions are assumed. Arguments are constructed in defense or against the different positions until the issue is settled by convincing the opponents or decided by a formal decision procedure. (Kunz \& Rittel, 1970, pp. 1-2, emphasis in original).

Thus, the discussion unfolds as one tries to persuade others of one's point of view.

The gIBIS was a software platform used to conduct research on using hypertext, GSS, and rhetorical models to facilitate and capture software system design decisions and their rationale. gIBIS was a prototype software tool for building and browsing IBIS networks (Conklin \& Begeman, 1988; Conklin \& Yakemovic, 1991). It provided a graphical interface and had a limited GSS capability, allowing several users to contribute to an IBIS discussion synchronously.

The IBIS method makes it "harder for discussants to make unconstructive rhetorical moves, such as 'argument by repetition' and name calling, and it supports other more constructive moves, such as seeking the central issue, asking questions as much as giving answers, and being specific about the supporting evidence of one's viewpoint" (Conklin \& Begeman, 1988, p. 305). Especially relevant in addressing social influences, users of the IBIS method report that the structure that IBIS imposes on discussions served to expose "axe grinding, hand waving, and clever rhetoric" and that they valued the tendency for assumptions and definitions to be made explicit (Conklin \& Begeman, 1988, p.323).

The semistructured nature of IBIS accounts for some of these advantages (Malone, Grant, Lai, Rao, \& Rosenblitt, 1986). The IBIS structure does not place any constraint on the writer when it comes to expressibility. At the same time, the reader is provided with the recurrent structure in the textual material that aids both search and comprehension (Conklin \& Begeman, 1988). 
As with other DR, an IBIS-based approach can be primarily descriptive or prescriptive; some are a combination of both (Dutoit et al., 2006). Descriptive approaches aim to portray designers' thinking processes and emphasize the issue base as a history of the design process; they do not seek to modify designers' reasoning. In contrast, prescriptive approaches seek to improve the design process by improving the reasoning of designers. This is done through a prescribed process to be followed, as the issue-base structure is developed through debate and discussion.

\section{Two Examples of IBIS-based DR Approaches}

In this section, two examples of IBIS-based DR approaches are presented. Each approach is supported by computerized tools.

\section{Wisdom Approach}

Wisdom is both a prescriptive approach and a tool that is intended for use by project stakeholders during the early problem definition stage of RE (MacKenzie et al., 2005; Rooksby, Sommerville, \& Pidd, 2006). Rather than leading to finalized requirements, the goal of Wisdom is to achieve a common understanding of the problem to be addressed before moving forward. The prescribed process, described below and highlighted in Table 2, incorporates two problemstructuring techniques: cognitive mapping and dialogue mapping using IBIS.

Brainstorming, the first step in the process, is used to encourage divergent thinking about relevant issues and concerns in broad terms (see previous discussion on Brainstorming for a description of the process steps). If a form of nominal group technique is desired, then each participant brainstorms individually by typing their ideas into their computer whereby only the facilitator and the system chauffeur can identify the contributor. Otherwise, a cooperative (nonanonymous) brainstorming technique is used.

Cognitive mapping (Tolman, 1948) is the second step in the process and provides a macro view of the problems. A cognitive map is a representation of how an individual views or thinks about a situation and, as such, can be viewed by others. It includes nodes that represent concepts and directional arcs that indicate linkages and causality between concepts. In the Wisdom approach, the facilitator creates a map that identifies participants' concerns and issues. The goal is for the group to identify key issues and to gain agreement, which normally

Table 2. Steps in the Wisdom Approach.

\section{Step Description}

(1) Brainstorming An anonymous or co-operative (non-anonymous) brainstorming technique is used to encourage divergent thinking about relevant issues and concerns in broad terms.

(2) Cognitive mapping

The facilitator creates a cognitive map that identifies participants' concerns and issues. The goal is for the group to identify key issues and to gain agreement, which requires debate and possible voting in the negotiation process.

(3) Dialogue mapping

Using IBIS notation, participants create a dialogue map for each key issue. Maps are linked using hypertext. 
requires debate and negotiation, and possibly voting. The result of the cognitive mapping step is to reach agreement on and commitment to a way forward.

Dialogue mapping is the third step and is used after key issues have been identified during cognitive mapping. Using IBIS notation - specifically question, idea, and argument node types - participants create a dialogue map for each key issue, using hypertext to link them as appropriate. Dialogue mapping provides a micro view of the issues and promotes "rigorous discussion and analysis of individual issues" (Rooksby et al., 2006, p. 142)

The tool consists of an application that runs on the facilitator's laptop. The tool provides network connectivity that supports individual brainstorming during a meeting. The facilitator creates the map, which is projected onto a shared display. Thus, participants' use of the tool is indirect. A Web interface supports asynchronous work prior to the meeting.

The Wisdom designers (Rooksby et al., 2006) describe the importance of the facilitator:

The effectiveness of a meeting is dependent on the skills of a neutral facilitator [9, 30]. The facilitator's objective is to foster procedural rationality, where stakeholders agree that sensible decisions have been made and commit to them. In practice, a facilitator ensures that a meeting remains focused, that the evolving cognitive map accurately reflects the ongoing discussion, that stakeholders get the opportunity to air their views and that the decision process is sensible. (p. 142-143).

\section{WinWin Approach}

WinWin is an example of a descriptive approach to design rationale. It is a "set of principles, practices, and tools, which enable a set of interdependent stakeholders to work out a mutually satisfactory 'win-win' set of shared commitments" (Boehm \& Kitapci, 2006, p.78). WinWin is built on the spiral model, which combines the features of the prototyping and waterfall models (Boehm, 1988). With the intent of risk management, the spiral model is an incremental development methodology that consists of a series of cycles. Each spiral cycle consists of four phases: determine objectives, identify and resolve risks, develop and test, and plan the next iteration.

WinWin adds a negotiation process to the front end of each spiral cycle. The negotiation activities consist of (a) identifying "success-critical" stakeholders, (b) eliciting the stakeholders' "win" conditions, (c) negotiating mutually satisfying win-win conditions between stakeholders, and (d) monitoring and control of a win-win balance during development.
Stakeholders express their goals as win conditions. If everyone concurs, the win conditions become agreements. When stakeholders do not concur, they identify their conflicted win conditions and register their conflicts as issues. In this case, stakeholders invent options for mutual gain and explore the option trade-offs. Options are iterated and turned into agreements when all stakeholders concur. (Boehm \& Kitapci, 2006, p. 180)

The EasyWinWin tool embeds the WinWin negotiation process within a GSS (i.e., GroupSystems). As indicated in Table 3, the negotiation process includes steps where stakeholders (a) review and expand negotiation topics, (b) brainstorm, (c) converge on win conditions, (d) prioritize win conditions, (e) reveal issues and constraints, (f) identify issues and options, and $(\mathrm{g})$ negotiate agreements. 
Table 3. EasyWinWin Negotiations Steps.

\begin{tabular}{|c|c|}
\hline Step & Description \\
\hline Review \& expand negotiation topics & Jointly build an outline of topics \\
\hline Brainstorm & Share goals, perspectives, expectations \\
\hline Converge on win conditions & $\begin{array}{l}\text { Discuss ideas from brainstorming session to jointly } \\
\text { develop list of win conditions }\end{array}$ \\
\hline Prioritize win conditions & Vote on win conditions to determine priorities \\
\hline Reveal issues and constraints & Surface and understand issues \\
\hline Identify issues and options & $\begin{array}{l}\text { Surface issues due to constraints, risks, uncertainties, } \\
\text { and conflicting win conditions }\end{array}$ \\
\hline Negotiate agreements & Establish mutual commitments by formulating win conditions \\
\hline
\end{tabular}

The designers (Boehm \& Kitapci, 2006) state that,

The focus on consensus leads to a higher acceptance of decisions and to an increased mutual understanding among the involved parties. The evaluation of the WinWin model shows that the use of an issue model of negotiation support enhances trust and shared understanding among shareholders, even in the presence of uncertainties and changing requirements. (p. 187)

\section{CRITIQUE AND CONCLUSIONS}

I conclude by critiquing the Wisdom and WinWin approaches in terms of addressing social influences and offer suggestions for enhancing the approaches in order to explicitly address social influences to promote creativity. Both Wisdom and WinWin recognize the importance of including key stakeholders in order to identify requirements and reach agreement on substantive issues before moving a project forward. Both include brainstorming to generate ideas, issue surfacing and representation as well as negotiation to reach agreement.

West (1990) proposed that creative teams operate in an environment of participative safety (a nonjudgmental and supportive team atmosphere) and foster a climate for excellence (exhibiting a tolerance for diversity of opinion and constructive conflict). However, the manner in which stakeholders are included in each approach tends toward an ideal view of group interaction (i.e., all participants' viewpoints are encouraged, and all participants feel equally valued and willing to share diverse or controversial viewpoints). The Wisdom and WinWin approaches both rely heavily on meeting facilitators to create and maintain a supportive atmosphere. However, expert facilitators can be scarce. In their absence, processes may not be carried out as their designers intended.

I suggest that a stakeholder analysis be conducted as an initial step. This analysis should result in an understanding of pre-existing relationships between stakeholder groups and identify existing or potentially conflicting interactions between key stakeholder groups. Given the outcome of the stakeholder analysis, and a tool such as EasyWinWin, anonymity can be incorporated throughout the remaining steps (e.g., anonymous EBS, anonymous voting, and 
anonymous issue surfacing and representation are all likely candidates). Thus, the potential for negative social influences (i.e., status differentials, social identity, and majority influence), all of which breed conformity as opposed to creativity, can be explicitly addressed.

Furthermore, by embedding steps that address social influences, less dependence is placed on the skills of a facilitator and the benevolence of stakeholder groups. The result is that negative social influences have the potential to be side-stepped. Thus, a group context conducive to a more egalitarian and participative exchange of ideas is promoted, which in turn, is more favorable to group creativity.

In conclusion, there is a need to instill awareness of the potential for negative social influences throughout the RE process. Negative social influences should be addressed in a deliberate manner in order to promote creativity in the requirements engineering process.

\section{ENDNOTE}

1. For more information, see GroupSystems.com

\section{REFERENCES}

Amabile, T. M. (1988). A model of creativity and innovation in organizations. Research in Organizational Behavior, 10, 123-167.

Amabile, T. M. (1990). Within you, without you: The social psychology of creativity, and beyond. In M. A. Runco \& R. S. Albert (Eds.), Theories of creativity (pp. 61-91). Newbury Park, CA, USA: Sage.

Asch, S. E. (1951). Effects of group pressure upon the modification an distortion of judgments. In H. Guetzkow (Ed.), Groups, leadership, and men (pp. 177-190). Pittsburgh, PA, USA: Carnegie Press.

Barron, F. B., \& Harrington, D. M. (1981). Creativity, intelligence, and personality. Annual Review of Psychology, 32, 439-476.

Biernat, M., \& Kobrynowicz, D. (1997). Gender and race-based standards of competence: Lower minimum standards but higher ability standards for devalued groups. Journal of Personality and Social Psychology, $72,544-557$.

Boehm, B. (1988). A spiral model of software development and enhancement. Computer, 21(5), 61-72.

Boehm, B., \& Kitapci, H. (2006). The WinWin approach: Using a requirements negotiation tool for rationale capture and use. In A. H. Dutoit, R. McCall, I. Mistrik, \& B. Paech (Eds.), Rationale management in software engineering (pp. 173-190). Berlin, Germany: Springer-Verlag.

Bos, N., Shami, N. S., Olson, J. S., Cheshin, A., \& Nan, N. (2004). In-group/out-group effects in distributed teams: An experimental simulation. Computer Supported Cooperative Work (CSCW), 6, 429-436.

Carroll, J. B. (1993). Human cognitive abilities. New York, NY: Cambridge University Press.

Cohen, B. P., \& Zhou, X. (1991). Status processes in groups. American Sociological Review, 56, $179-188$.

Conklin, J., \& Begeman, M. (1988). gIBIS, A tool for exploratory policy discussion. ACM Transactions on Office Information Systems (TOOIS), 6, 303-331. Conklin, J., \& Yakemovic, K. C. (1991). Process-oriented design rationale. Human-Computer Interaction, 357-391.

Connolly, T., Routhieaux, R. L., \& Schneider, S. K. (1993). On the effectiveness of group brainstorming. Small Group Research, 24, 490-503.

Connolly, T., Jessup, L. M., \& Valacich, J. S. (1990), Effects of anonymity and evaluative tone on idea generation in computer-mediated groups. Management Science, 36, 689-703.

Cottrell, N. B. (1972). Social facilitation. In C. McClintock (Ed.), Experimental social psychology (pp. 185236). New York: Holt, Rinehart \& Winston.

Couger, J. D. (1996). Creativity \& innovation in information systems organizations, Danvers, MA, USA: Boyd $\&$ Fraser. 
Cramton, C. D., \& Hinds, P. J. (2005). Subgroup dynamics in internationally distributed teams: Ethnocentrism or cross-national learning. Research in Organizational Behavior, 26, 231-263.

Diehl, M., \& Stroebe, W. (1987). Productivity loss in brainstorming groups: Toward the solution of a riddle. Journal of Personality and Social Psychology, 53, 497-509.

Dutoit, A. H. (2006). Rationale management for requirements engineering.and In A. H. Dutoit, R. McCall, I. Mistrik, \& B. Paech (Eds.), Rationale management in software engineering (pp. 132-136). Berlin, Germany: Springer-Verlag.

Dutoit, A.H., McCall, ., Mistrik, I, \& Paech, B. (2006). Rationale management in software engineering: Concepts and Techniques. In A. H. Dutoit, R. McCall, I. Mistrik, \& B. Paech (Eds.), Rationale management in software engineering (pp. 1-48). Berlin, Germany: Springer-Verlag.

Festinger, L. (1950). Informal social communication, Psychological Review, 57, 271-282.

Fischer, G. (1990). Cooperative knowledge-based design environments for the design, use and maintenance of software. In Proceedings of the Software Symposium 90 (pp. 2-22). Kyoto, Japan.

Fjermestad, J., \& Hiltz, S. (1998). An assessment of group support systems experimental research: methodology and results. Journal of Management Information Systems, 15(3), 7-149.

Fjermestad, J., \& Hiltz, S. (2000). Group support systems: A descriptive evaluation of case and field studies source. Journal of Management Information Systems, 17(3), 115-159.

Gallupe, R. B., \& Cooper, W. H. (1993). Brainstorming electronically. Sloan Management Review, 35, $27-36$.

Graham, D. (1962). Experimental studies of social influence in simple judgment situations. Journal of Social Psychology, 56, 245-269.

Guilford, J. P. (1977). Way beyond the IQ. Amherst, MA, USA: Creative Education Foundation Press.

Guilford, J. P. (1984). Varieties of divergent production. Journal of Creative Behavior, 18, 1-10.

Hoffman, L. R. (1959). Homogeneity of member personality and its effect on group problem-solving. Journal of Abnormal Social Psychology, 58, 27-32.

Hoffman, L. R., \& Maier, N. R. F. (1961). Quality and acceptance of problem solutions by members of homogeneous and heterogeneous groups. Journal of Abnormal Social Psychology, 62, 401-407.

Hollander, E. P. (1964). Leader, groups, and influence. New York: Oxford University Press.

Holtzblatt, K., \& Beyer, H. R. (1995). Requirements gathering: The human factor. Communications of the ACM, $38(5), 31-32$.

Kanter, R. M. (1977). Some effects of proportions in group life: Skewed sex ratios and responses to numerical minority women. American Journal of Sociology, 82, 965-990.

King N., \& Anderson, N. (1990). Innovation in working groups. In M. West \& J Farr (Eds.), Innovation and creativity at work (pp. 81-100). Chichester, UK: Wiley and Sons.

Kunz, W., \& Rittel, H. (1970). Issues as elements of information systems (Working paper No. 131), available from the, Institute of Urban and Regional Development, University of California at Berkeley, http://iurd.berkeley.edu/sites/default/files/wp/131.pdf

Latane B. (1981). The psychology of social impact. American Psychology, 36, 343-356.

Lau, D. C., \& Murnighan, J. K. (1998). Demographic diversity and faultlines: The compositional dynamics of organizational groups. Academy of Management Review, 23, 325-340.

Lim, J., \& Guo, X. (2008). A study of group support systems and the intergroup setting. Decision Support Systems, 45, 452-460.

Lott, A., \& Lott, B. (1965). Group cohesiveness as interpersonal attraction: A review of relationships with antecedent and consequent variables. Psychological Bulletin, 64, 259-309.

Maass, A., \& Clark, R. D. (1984). Hidden impact of minorities: Fifteen years of minority influence research. Psychological Bulletin, 95, 428-450.

Malone, T. W., Grant, K., Lai, K.-Y, Rao, R., \& Rosenblitt, D. (1986). Semi-structured messages are surprisingly useful for computer-supported coordination. In D. Peterson (Ed.), Proceedings of CSCW'86, MCC/ACM Conference on Computer-Supported Cooperative Work (pp. 102-114). Austin, TX, USA: ACM Press.

MacKenzie, A., Pidd, M., Rooksby, J., Sommerville, I., Warren, I., \& Westcombe, M. (2005).Wisdom: Decision support and paradigms of decision making. European Journal of Operational Research, 170, 156-171.

Moreland, R. L., \& Levine, J. M. (1992). The composition of groups. In E. J. Lawler, B. Markovsky, C. Ridgeway, \& H. A. Walker (Eds.), Advances in group processes (Vol. 9; pp. 237-280). Greenwich, CT, USA: JAI.

Moscovici, S. (1974). Social influence, I: Conformity and social control. In C. Nemeth (Ed.), Social psychology: Classic and contemporary integrations (pp. 179-216). Chicago: Rand McNally. 
Moscovici, S., \& Nemeth, C. (1974). Social influence, II: Minority influence. In C. Nemeth (Ed.), Social psychology: Classic and contemporary integrations (pp. 217-249). Chicago: Rand McNally.

Mouton, J. S., Blake, R. R., \& Olmstead, J. A. (1956). The relationship between frequency of yielding and the disclosure of personal identity. Journal of Personality, 24, 339-347.

Mullen, B., Johnson, C., \& Salas, E. (1991). Productivity loss in brainstorming groups: A meta-analytic integration. Basic and Applied Social Psychology, 12(1), 3-23.

Nemeth, C. J. (1986). Differential contributions of majority and minority influence, Psychological Review, 93, $23-32$.

Nguyen, L., \& Swatman, P. A. (2006). Promoting and supporting requirements engineering in creativity. In A. H. Dutoit, R. McCall, I. Mistrik, \& B. Paech (Eds.), Rationale management in software engineering (pp. 209-230). Berlin, Germany: Springer-Verlag.

Ocker, R. J. (2005). Influences on ceativity in asynchronous virtual teams: A qualitative analysis of experimental teams. IEEE Transactions on Professional Communication, 48, 22-39.

Ocker, R. J. (2007a). A balancing act: The interplay of status effects on dominance in virtual teams. IEEE Transactions on Professional Communication, 50, 204-218.

Ocker, R. J. (2007b). Creativity in asynchronous virtual Teams: Putting the pieces together. In T. Torrres \& S. MacGregor (Eds.), Higher creativity for virtual teams: Developing platforms for co-creation (pp. 26-47). Hershey, PA, USA: Idea Group.

Ocker, R. J., Huang, H., Benbunan-Fich, R., \& Hiltz, S.R. (in press). Leadership dynamics in partially distributed teams: An exploratory study of the effects of configuration and Distance. Group Decision and Negotiation.

O'Reilly, C., Caldwell, D., \& Barnett, W. (1989). Work group demography, social integration, and turnover. Administrative Science Quarterly, 34, 21-37.

Osborn, A. F. (1963). Applied imagination: Principles and procedures of creative problem solving (3rd rev. ed.). New York: Charles Scribner's Sons.

Panteli, N., \& Davison, R. M. (2005). The role of subgroups in the communication patterns of global virtual teams. IEEE Transactions on Professional Communication, 48, 191-200.

Parmeter, S. M., \& Gaber, J. D. (1971). Creative scientists rate creativity factors. Research Management, 14, 65-70.

Polzer, J. T., Crisp, C. B., Jarvenpaa, S. L., \& Kim, J. W. (2006). Extending the faultline concept to geographically dispersed teams: How colocated subgroups can impair group functioning. Academy of Management Journal. 49, 679-692.

Rittel, H., \& Webber, M. (1973). Dilemmas in a general theory of planning. Policy Sciences, 4, 155-169.

Rooksby, J., Sommerville, I., \& Pidd, M. (2006). A hybrid approach to upstream requirements: IBIS and cognitive mapping. In A. H. Dutoit, R. McCall, I. Mistrik, \& B. Paech (Eds.), Rationale management in software engineering (pp. 137-154). Berlin, Germany: Springer-Verlag.

Sell, J., Lovaglia, M. J., Mannix, E. A., Samuelson, C. D., \& Wilson, R. K. (1992). Investigating conflict, power, and status within and among groups. Small Group Research, 35, 44-72.

Sherif, M. (1935). The psychology of social norms. New York: Harper \& Row.

Smith, J. B., Weiss, S. F., Ferguson, G. J., Bolter, J. D., Lansman, M. L., \& Berad, D. V. (1986). WE: A writing environment for professionals (Tech. Rep. No. 86-025). University of North Carolina at Chapel Hill, USA, Department of Computer Science.

Smith, K., Smith, K., Olian, J., Sims, H., O’Bannon, D., \& Scully, J. (1994). Top management team demography and process: The role of social integration and communication. Administrative Science Quarterly, 39, 412-438.

Tajfel, H. (1978). Differentiation between social groups: Studies in the social psychology of intergroup relations. London: Academic Press.

Tajfel, H. (1981). Human groups and social categories: Studies in social psychology. Cambridge, UK: Cambridge University Press.

Tajfel, H., \& Turner, J. C. (1986). The social identity theory of intergroup behaviour. In S. Worchel \& W. G. Austin (Eds.), Psychology of intergroup relations (pp. 7-24). Chicago: Nelson.

Thompson, L. (2003). Improving the creativity of organizational work groups. Academy of Management Executive, 17, 96-109.

Tolman E. C. (1948). Cognitive maps in rats and men. Psychological Review, 55,189-208. .

Toulmin, S. E. (1958). The uses of argument. Cambridge, UK: Cambridge University Press. 
Turner, J. C. (1981). The experimental social psychology of intergroup behaviour. In J. C. Turner \& H. Giles (Eds.), Intergroup Behaviour (pp. 66-101). Oxford, UK: Basil Blackwell.

Vinacke, W. E., Wilson, W. R., \& Meredith, G. M. (1964). Dimensions of social Psychology. Chicago: Scott, Foresman and Co.

Wagner, D., \& Berger, J. (1993). Status characteristics theory: The growth of a program in theoretical research programs. In J. Berger \& M. Zeldich, Jr. (Eds.), Studies in the growth of theory (pp. 23-63). Stanford, CA, USA: Stanford University Press.

Wagner, D., \& Berger, J. (1997). Gender and interpersonal task behaviors: Status expectation accounts. Sociological Perspectives, 40, 1-32.

Walz, D. B., Elam, J. J., \& Curtis, B. (1993). Inside a software design team: Knowledge acquisition, sharing and integration. Communications of the ACM, 36(10), 63-77.

West, M. A. (1990). The social psychology of innovation in groups. In M. West \& J. Farr (Eds.), Innovation and creativity at work (pp. 309-333). Chichester, UK: Wiley and Sons.

Williams, K. Y., \& O’Reilly, C. A. (1998). Demography and diversity in organizations: A review of 40 years of research. Research in Organizational Behavior, 20, 77-140.

Woodman, R., \& Schoenfeldt, L. F. (1989). Individual differences in creativity: An interactionist perspective. In J. A. Glover \& C. R. Reynolds (Eds.), Handbook of creativity (pp. 77-92). New York: Plenum Press.

Woodman, R., Sawyer, J., \& Griffin, R. (1993). Toward a theory of organizational creativity. Academy of Management Review, 18, 292-321.

\section{Authors' Note}

All correspondences should be addressed to

Rosalie J. Ocker

College of Information Sciences and Technology

The Pennsylvania State University

University Park, PA 16801

rocker@ist.psu.edu

Human Technology: An Interdisciplinary Journal on Humans in ICT Environments

ISSN 1795-6889

www.humantechnology.jyu.fi 